\title{
CYBER SECURITY MASTER'S DEGREES IN THE UNITED KINGDOM: A COMPARATIVE ANALYSIS
}

\author{
Anna Urbanovics ${ }^{1}$ and Peter Sasvari ${ }^{2}$
}

DOI: 10.24989/ocg.338.13

\begin{abstract}
In today's digitized world, where most of our activities are related to online platforms, the information security has become more essential than ever. Most countries have launched national strategies for the implementation of cyber security. In these, the education and training of information security professionals get particular roles. The National Cyber Security Centre created a common framework for cyber security education in the United Kingdom for the universities offering degrees in information security. The aim of this paper is to examine and compare the British cyber security degrees. The first chapter examines and compares the British universities and degrees from a theoretical aspect, including the necessity of these programs. The second chapter examines the degrees from several aspects based on the data of the Scopus database, with a special focus on the thematic modules, and the academic activities of the 1,650 examined university instructors.
\end{abstract}

Keywords: cyber security education, National Cyber Security Centre, United Kingdom, Scopus

\section{Introduction}

Greater dependence on the Internet has brought new kinds of dangers and challenges related to cyberspace. Since we store a large part of our data in cyberspace and create personal profiles with different functions, we have become virtually predictable and vulnerable [3].

Cybercrime is a completely new dimension of crimes, affecting the whole world beyond borders Governments and national security organizations must counter these crimes, design regulations and strategies for effective defence. [6] At the same time, it is a global challenge that we all must tackle through precautionary measures and correct use of the Internet. In most cases, criminals try to exploit these gaps and shortcomings, so information security education and awareness have become a basic need. [5] Many positive effects can be observed by cyber security education reducing vulnerability at individual, organizational and national levels.

Our article aims to provide a research focus comparison of cyber security master's degrees in the United Kingdom based on empirical analysis. The selected universities have obtained full certificate of the National Cyber Security Centre and they are highly ranked institutions by the QS World University Rankings ${ }^{3}$.

\footnotetext{
${ }^{1}$ Student, National University of Public Service, 1083 Budapest, Üllői út 82., Hungary, anna.urbanovics@gmail.com

${ }^{2}$ Ph.D., senior lecturer, National University of Public Service, Department of Public Management and Information Technology, 1083 Budapest, Üllöi út 82., Hungary, sasvari.peter@uni-nke.hu

${ }^{3}$ The Quacquarelli Symonds (QS) World University Rankings is an annual publication of university rankings. The QS system now comprises the global overall and subject rankings.
} 
The article follows scientometric approach, research collaboration and research activities will be emphasized. The empirical analysis is based on data from a 20-year scale ranging from 1996 to 2006 available on SciVal and Scopus. Scopus database is one of the main citation catalogues of internationally recognized, high impact research articles and due to this, university rankings. Both the QS University Ranking and THE Times University Ranking insist on bibliometric data gathered from Scopus database when measuring the research impact of academic. In university rankings one of the most objective indicators is the bibliometric indicator, although some factors, for example the size of the university influence them significantly. For this reason, in the following analysis, per capita (academic) or per document averages are analyzed. The structure of degrees will be compared as well. In addition to providing an overview of the United Kingdom's information security degrees, our article aims to give recommendations on publication strategies based on the empirical results.

\section{Need for cyber security degrees}

Due to the proliferation of cyberattacks and their potential as a new global challenge, the organization of cyber security education should be included within the priorities of states. These trainings focus primarily on how to prevent the attacks and reduce the risk factors, aiming to train well-prepared professionals. This kind of cyber security knowledge enables professionals to take further steps in organizing effective defence.

The official websites of the British universities offering cyber security degrees emphasize the wide range of employment opportunities that attracts many youngsters. There is a huge demand for cyber security professionals both at the public and private sphere. [8] Four main categories can be divided among the actors of cyber security. University lecturers and academics dealing with the theoretical elements of the discipline; professionals hired in the private sphere and industry; employees in the public sphere and finally the members of the society who have information security awareness. [1]

Cyber Security education can help to increase the awareness of the society for the correct Internet use. Consciousness and self-confident use of different online applications can also enhance people's trust which is a very important factor in developed, isolated societies. In these countries, information security is among the top priorities of the state. National strategies have also been formulated with the common point of providing basic education for every student in elementary schools.

University degrees aim to provide theoretical and practical knowledge at the same time. The theoretical background is essential to deepen and expand the discipline with new methods and techniques. Its purpose is to enable professionals to keep up with criminals and be able to supervise the security systems. Practical knowledge will help them to deal with different situations in their workplaces later. This does not include only information security knowledge but also specific skills and abilities essential in the business world. Students can choose from different degree structures, all beginning with a bachelor's degree in computer sciences and continuing with more specific master's degrees.

\section{Degrees of the National Cyber Security Centre}

In the field of computer sciences, the dominance of the anglophone states is undisputable regarding the university degrees. Based on the list of QS World University Rankings, we can see that eight of the top ten universities were anglophone in 2016. The list is headed by two universities of the Unites States, the Massachusetts Institute of Technology (MIT) and Stanford University, followed by the British University of Oxford at the 3rd place. The British universities selected for the analysis are in 
the first 350 places which is a good result on the top 500 world ranking. Seven institutions (meaning the half of the studied universities) are ranked among the top 150.

The UK government set up the National Cyber Security Centre on the 1st of January in 2016 and created the National Cyber Security Strategy for 2016-2021. Chapter 7 of the Strategy deals with cyber security education. The state aims to balance supply and demand by offering competitive university degrees and continuous trainings. In accordance with the strategy, a system has been established for British universities which aims to synchronize the curriculum and course structures. Although many British universities offer cyber security degrees, only the best are awarded by the certificate of the National Cyber Security Centre. This helps universities to attract the best students and to recruit well-trained lecturers. In order to obtain the certificate, an institution has to submit a tender including the names of the academics (involved to the cyber security program), the names of courses, the assessment plan, some drafts of thesis, the entry requirements, the thesis already submitted, the student IDs, and their feedback on the degree. The list of the awarded universities can be retrieved from the official website of the National Cyber Security Centre including the institutions with full and provisional certificates. 13 universities offering master's degrees have been chosen from the list for further analyses.

\section{Structure of degrees}

For the very first time, Eugene Spafford [7] defined the areas which every cyber security degree must contain. In his research, he identified 18 subtopics as the following: computer architecture, criminology and law, cryptography, database management, analysis of human-computer interaction, information acquisition, theory of information, management and business aspects of information, mathematics, military sciences, mobile computing, networks, operation systems, philosophy and ethics, programming languages, software development, statistics and probability and finally the web programming.

Basically, seven major modules can be identified and classified into distinct groups, in which the courses are interdependent and cumulative based on proposed course structures of the universities. Each group contains overlaps and common points, but they have well-defined topics and fields. Each category includes 3-4 courses in the master's degree structure. The structure of each university can be analysed and compared through these seven modules, because although they all have specialized courses according to their main scientific profiles, the main structure is unified. Due to unified structure of cyber security degree, National Cyber Security Centre can develop common guidelines efficiently. It is not a unique model however, other countries tend to harmonize their cyber security degrees as well, such as the United States.

The seven modules are:

- Cryptography and Data analysis,

- $\quad$ Forensics and Malware,

- Network security,

- $\quad$ Software security,

- Hardware security,

- $\quad$ IT from Other aspects (including law, management and psychology),

- $\quad$ Project and Research.

Based on the seven modules, it is worth noting the weight and impact of each subject in cyber security degrees as it is described in Figure 1. Most subjects have similar weight regarding the universities, 
but some shifts can be found between institutions in this respect. Among the modules, the Software security contains the second most courses (4th module), the least are on Hardware security (5th module). Most courses are related to the 6 th module because it covers several disciplines, for example law, management and psychology. These courses offer a more general aspect of information security. Courses in the 2nd module are the most closely related to the specific field of cyber security due to their main topics of forensic computing, but it appears that the courses of the 1st module are also emphasized. The courses of this module have the most mathematical nature, so the universities with social sciences profile do not teach them. The University of Southampton emphasizes the most on these courses of cryptography and data analysis, where four courses are built into the degree. This institution has an engineering profile which explains clearly the focus on mathematical approach of cyber security. The 6th module is the most widely taught, while the rarest is the 5th module. As regards to the course numbers two emerge, one is the Software security with 6 courses at the University of Birmingham, and the other is the Project and Research at the University of Southampton with 7 courses. The Queen's University Belfast has the least courses with 6, while the University of Southampton has the most with 18. The most structured degree is offered by the University of Southampton, where the courses are gathering around theoretical and business aspects, and cryptographic and data analysis skills.

\begin{tabular}{|c|c|c|c|c|c|c|c|}
\hline $\begin{array}{l}\text { University/ } \\
\text { Modul/ Number } \\
\text { of courses }\end{array}$ & \begin{tabular}{|c|} 
Cryptography \\
and Data \\
analysis \\
\end{tabular} & $\begin{array}{c}\begin{array}{c}\text { Forensics and } \\
\text { Malware }\end{array} \\
\end{array}$ & $\begin{array}{l}\text { Network } \\
\text { security }\end{array}$ & $\begin{array}{l}\text { Software } \\
\text { security }\end{array}$ & $\begin{array}{l}\text { Hardware } \\
\text { security } \\
\end{array}$ & \begin{tabular}{|c|}
$\begin{array}{c}\text { If from Other aspects } \\
\text { (including law } \\
\text { management } \\
\text { psychology) }\end{array}$ \\
\end{tabular} & $\begin{array}{c}\begin{array}{c}\text { Project and } \\
\text { Research }\end{array} \\
\end{array}$ \\
\hline & & 3 & 2 & 4 & & 3 & 2 \\
\hline $\begin{array}{l}\text { Lancaster } \\
\text { Univessity }\end{array}$ & & 2 & 1 & 1 & & 3 & 2 \\
\hline Irivant & & 1 & 2 & 2 & & 1 & 1 \\
\hline $0^{\circ}$ & 1 & 2 & 1 & 1 & & 1 & \\
\hline$\frac{x^{2}}{4 y^{2}}$ & 3 & 2 & 1 & 3 & 2 & 3 & 2 \\
\hline$\underline{\underline{L}}$ & 3 & 2 & & 2 & 1 & 3 & 3 \\
\hline 6. UNIVERSTYS & 3 & 1 & 3 & 6 & 1 & 1 & 3 \\
\hline 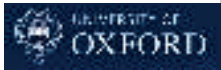 & 1 & 2 & 4 & 2 & & 5 & 1 \\
\hline 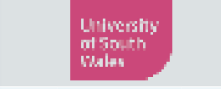 & & 3 & 1 & & & 2 & 1 \\
\hline Southampton & 4 & 2 & & 2 & 1 & 4 & 5 \\
\hline Io SURREY & 3 & & 2 & 2 & & 3 & \\
\hline of of 1 fork & 1 & 2 & 1 & & & 2 & 2 \\
\hline
\end{tabular}

Figure 1: Number of courses by modules and institutions 
After the analysis of the degree structures, we can observe that even if the degrees are unified in accordance with common guidelines, the universities create their own curricula based on their main profiles and proficiencies.

\section{Research activities of academics}

A total number of 1,651 academics' research activity were studied based on the Scopus database.

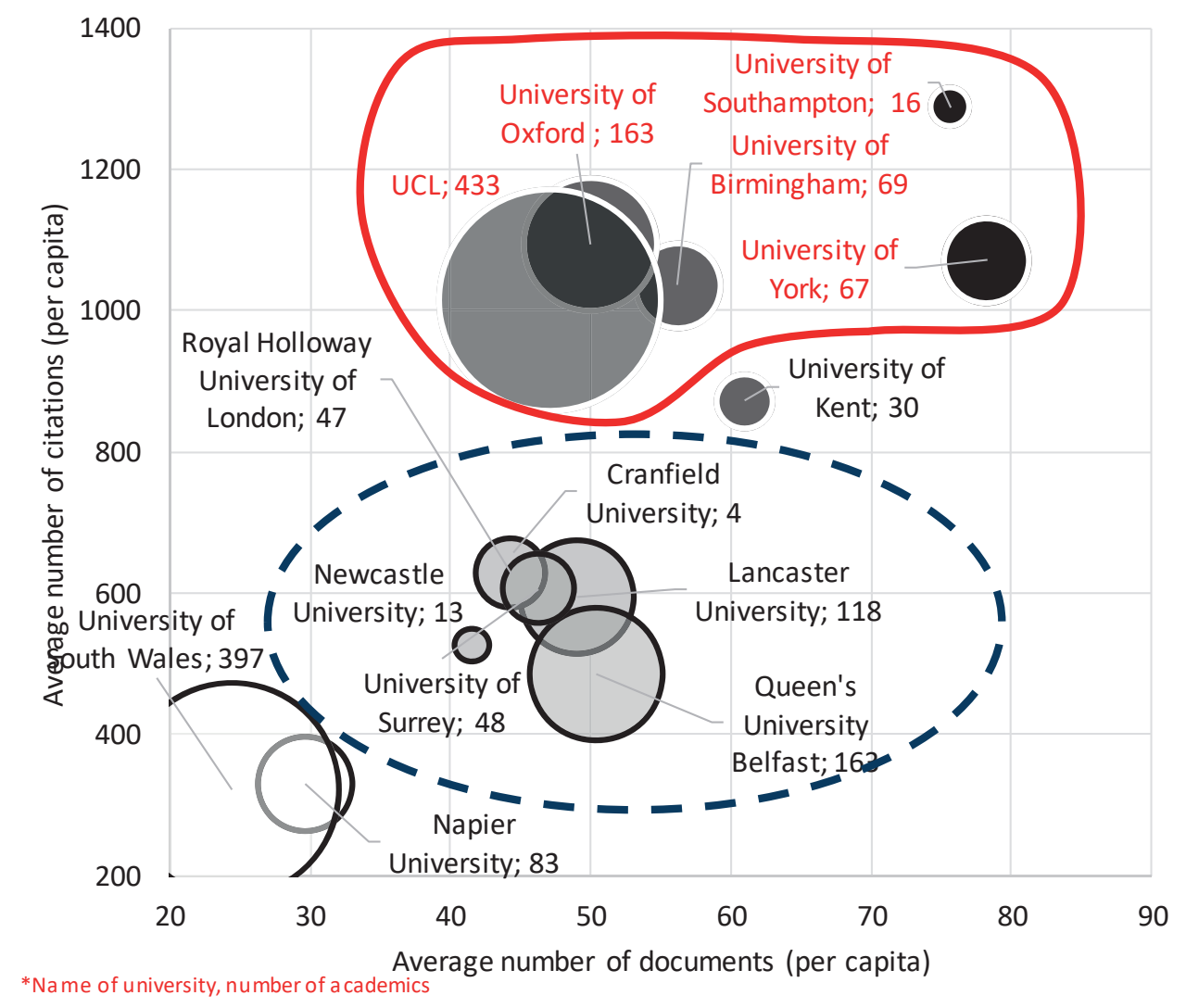

Figure 2: Number of citations, the average of documents per capita, and the number of cyber security researchers and lecturers by institutions

On Figure 2 a clustering of the examined universities can be observed based on the average number of documents per capita (academic) and average number of citations per documents. The size of the bubble shows the total number of academics involved in the analysis. These two factors define three distinct groups among the 14 examined universities as it is shown in Figure 2 by a clustering statistic. The grouping mechanism drives us to the different publication intensity. The universities in the first group can be described with intensive research and education activities. They are followed by a middle-class group in which the universities deal with research and education roughly at the same level of intensity but their scientific achievements is considered to be average. Cranfield University, Newcastle University, the University of Surrey, Lancaster University, Queen's University Belfast, and Royal Holloway University of London belong here. Within the evaluation a third category could be identified as well with universities dealing only with the education of cyber security. Their research activities are not significant in computer sciences. The Napier University and the University of South Wales are included here. The University of Kent is in a unique position because it does not belong to any of the groups since its publication intensity is somewhere between the top and middle-grouped universities regarding both factors. 
It can be observed that cyber security academics publish their research findings in many Scopusindexed publications. Primarily the University of York and the University of Southampton seem to be outstanding with high average document numbers, however in case of the University of South Wales (which has the lowest value) it scores up to 24 Scopus-indexed publications per capita.

\section{Research network}

It is worth noting the networks of researchers between institutions in the field of computer sciences. Figure 3 describes these networks including the strength of the correlations.

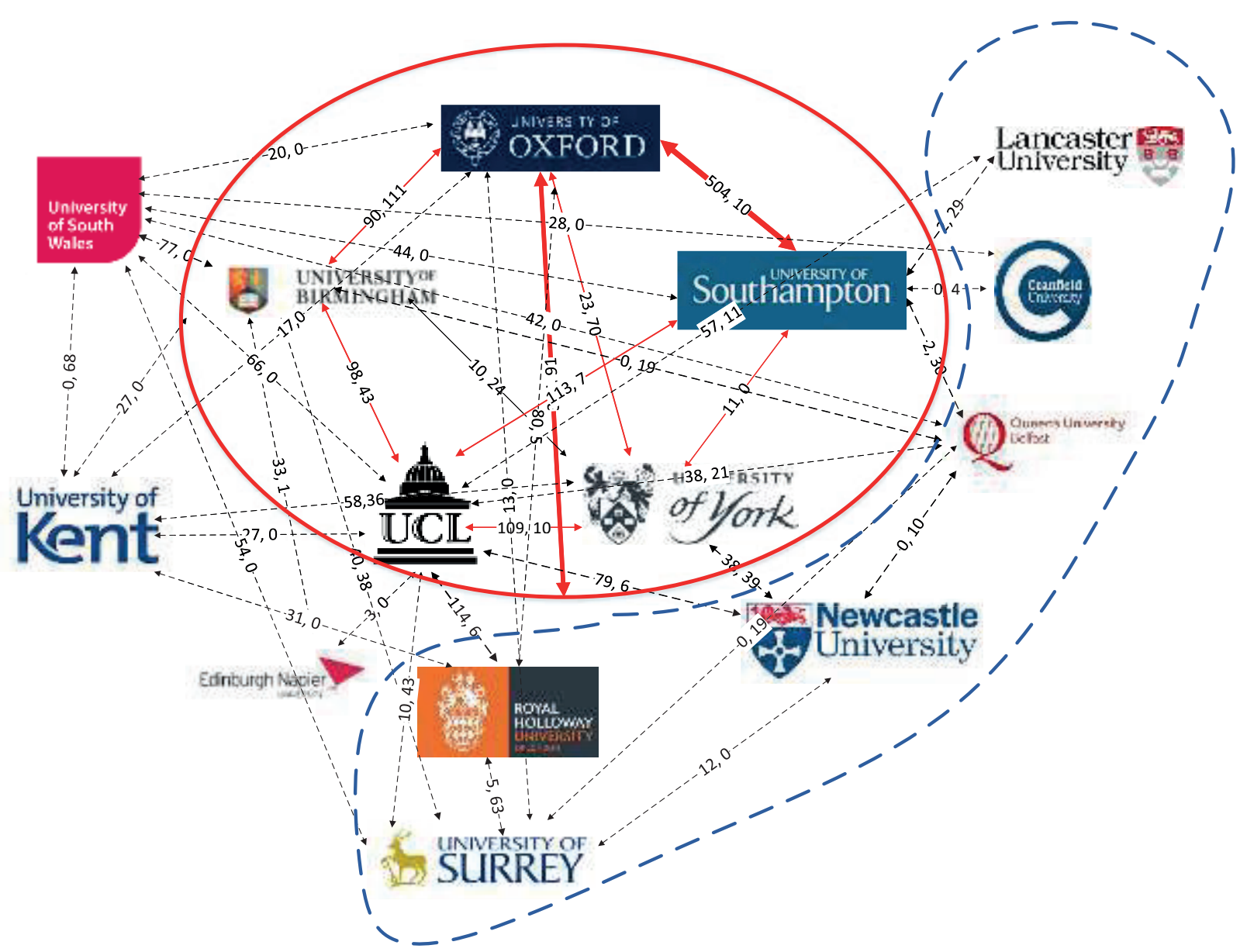

Figure 3: Cooperative networks of researchers in higher education institutions of the United Kingdom in the field of cyber security

The UCL is the most embedded with 911 articles published within the network, while the least embedded is the Cranfield University with 12 articles. The examined universities get $7.5 \%$ of their total publication within this network on average. The most cooperative is Newcastle University, where $13 \%$ of the whole amount of publications comes from this collaboration, while Queen's University Belfast has the lowest value of 1.7\%. As Figure 3 shows, universities with intensive IT research have the most relations with other institutions. Strong collaborations emerge between them, from which the most productive is the one between the University of Oxford and the University of Southampton. The University of Oxford, UCL, the University of Southampton, the University of York and the University of Birmingham are the most active when creating research network. The network of cyber security researchers is primarily seen at higher education institutions having intensive research on cyber security. 


\section{Scientific performance of academics}

Scientimetric analyses have been carried out regarding cyber security. [4] The 14 analysed universities have published a total of 60,583 articles in Scopus-indexed journals. 54,4\% of the articles were published after 2010 meaning 32,962 volumes. 2016 was the most productive year with 5,488 giving $9 \%$ of the total number of articles.

The fewest articles in the field of computer sciences were published by the Napier University (958), the University of South Wales $(1,252)$ and Cranfield University $(1,890)$. While the UCL $(9,502)$, the University of Oxford $(9,157)$ and the University of Southampton are the leaders, concerning the number of publications. The UCL has published 5,606 volumes since 2010 giving $59 \%$ of the total.

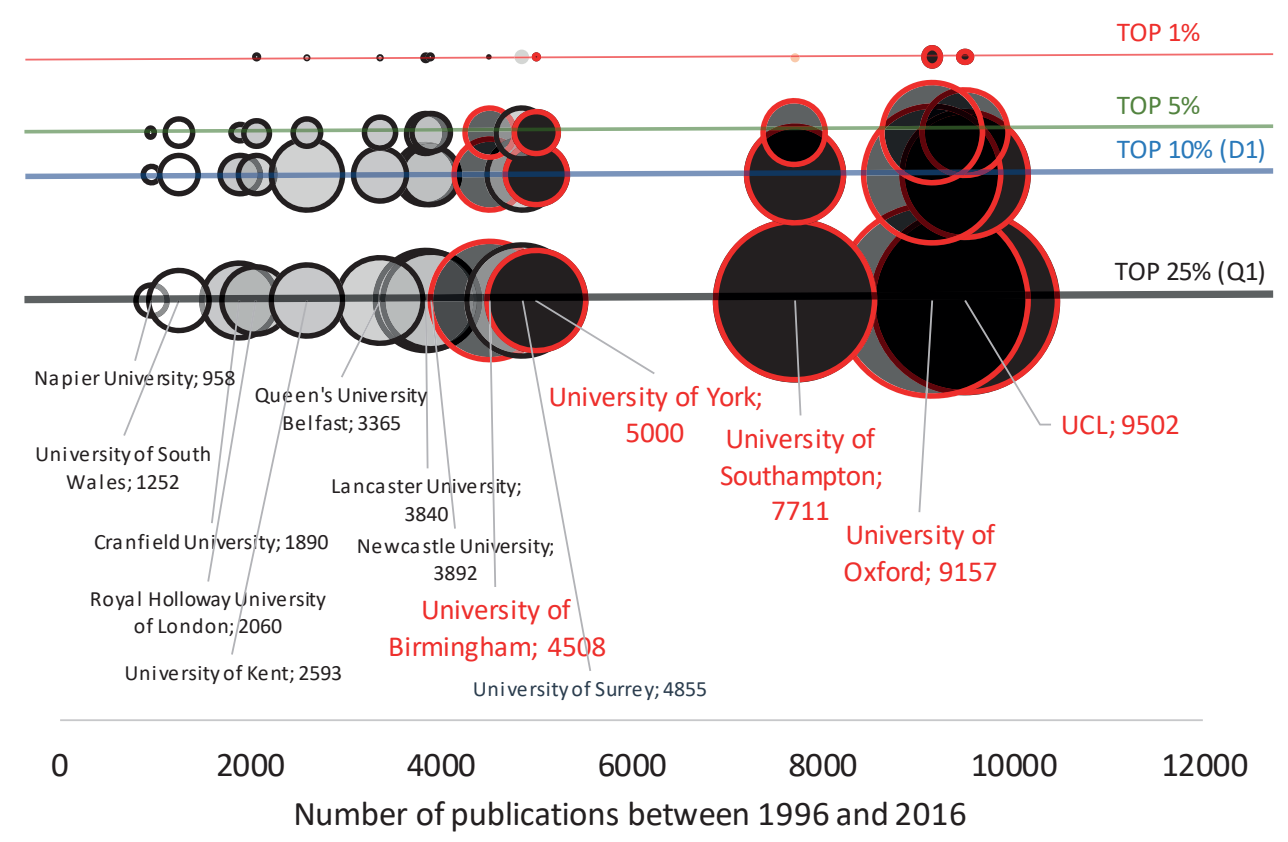

Figure 4: The total number of Q1, D1, TOP 5\% and TOP $1 \%$ articles published between 1996 and 2016 by British universities in computer sciences

Among the top 25\% (Q1) according to the SJR ranking, the 14 universities published a total of 13,328 articles at computer science between 1996 and 2016 as it is included in Figure 4. Since 2010, 7,813 units have been published, representing $58.6 \%$ of the total. Only in 2016, 1,472 publications were published, giving $11 \%$ of the total. The three least productive universities among the top $25 \%$ are the Napier University (95), the University of South Wales (305) and the Royal Holloway University of London (359). However, we can see that the Napier University's backlog is significant as its number of publications is just one-third of the University of South Wales. The three most productive universities are the University of Southampton $(1,854)$, the UCL $(2,421)$, and the University of Oxford $(2,681)$. The performance of the University of Oxford represents $20.1 \%$ of the total number of publications $(13,328)$. Since 2010, 1,643 articles have been published at the university among the top $25 \%$ journals giving $61.3 \%$ of the total. 2016 was the most successful year with 281 articles.

In the top 1\% journals according to SJR rankings, the analysed British universities published a total of 107 articles between 1996 and 2016 in computer sciences. From this, 35 were published in 2016 giving $32.7 \%$ of the total. Since 2010, 60 articles have been published, while in the last 5 (from 2012) 
52. This means that $56 \%$ of the total number were published in this decade. There are differences between the universities' performance. Three universities could not publish any articles in a top 1\% journal in computer sciences. These are the Cranfield University, the University of South Wales and the Napier University. The three most productive universities are the University of Surrey (14), the UCL (20) and the University of Oxford (37). The Oxford's performance is almost two times (1.85) higher than the UCL's. What is more, its performance shows a growing tendency by publishing 26 articles giving 70\% of their articles after 2010. In 2016, 18 articles were published which is almost the half $(48.6 \%)$ of their performance. With these results, 2016 was the most productive year for the University of Oxford, and this can be stated about the performance of the UCL (5) and the University of Surrey (7).

Even though the University of Oxford stands as second after the UCL regarding the quantity of the publications, when comparing the quality of the publications, it is the most productive university in every category (top $25 \%$, top $10 \%$, top $5 \%$ and top $1 \%$ ). The analysis based on the Scopus database give us the same results as the QS ranking that the higher ranked universities carry out more significant research activities. The members of the university groups mentioned before show the same picture with the leading of the University of Oxford and the UCL. These universities are ranked 6th and 7th in the QS world ranking in computer sciences that is reflected in the intensity and quality of cyber security research.

\section{Places of publication}

When analysing the citation index and reference numbers, we can observe that the most cited research publications are published in conference proceedings as the following figure (Figure 5) shows it.

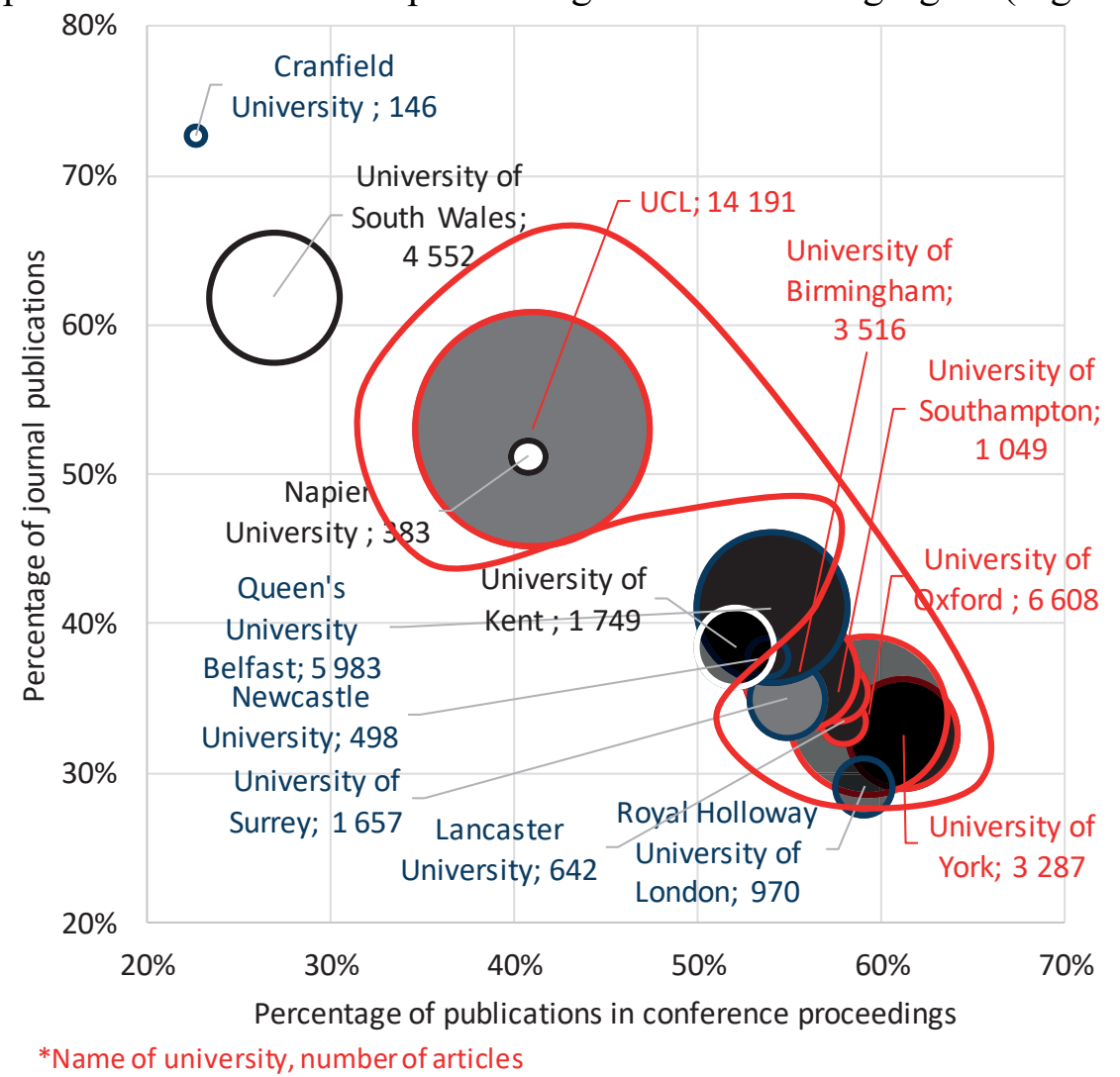

Figure 5: Form and places of publications by cyber security researchers and lecturers by institutions 
Among the five leading universities, only the UCL shows different behavioural patterns since it does not publish primarily in computer sciences. Thus, the general research and academic culture of the UCL prefers journal articles. It also appears that the middle-class universities dealing both with education and research try to catch up with the best universities and publish 50 to $60 \%$ of their publications in conference papers. The University of York is the most committed to conference volumes, publishing more than $60 \%$ of their total number of publications in conference papers. Being represented in conference papers, on the one hand, increases the total views because they are internationally accepted platforms of researchers, and on the other hand, it allows to publish the latest results quickly and at a high level. In a fast-changing discipline such as computer sciences these features, such as speed and up-to-date result communication play an important role. What is more, conference proceedings ensure high-quality publications even beside a more informal structure.

\section{Breakdown by disciplines}

It is also worth noting at which disciplines the lecturers publish their research publications. The publication has a clear and undisputed breakdown among three main disciplines. These are the computer sciences, engineering and mathematics as it is included in Figure 6.

A correlation can be observed because at the universities which hire more academics in these three disciplines, have bigger success and higher relevance in Cyber security sciences. There is also a correlation in this respect that universities with more educators who are active in these three disciplines are more successful in cyber security. Among the universities having intensive research and leading education, the University of York publishes $48 \%$ of the total publications in computer sciences but similarly high rates can be seen in the case of the University of Oxford (47\%), the University of Birmingham (42\%) and the University of Southampton (37\%). In this respect, UCL is somewhat different from this picture but the three disciplines together play a prominent role at this university as well. The ranking ends with Cranfield University, the University of South Wales and Napier University. In relation to the last two universities, it is important to mention that social sciences are emphasized in their academic profile, explaining the weaker results in the field of the three examined disciplines.

In conclusion, university lecturers at the examined universities mostly publish their research findings in three disciplines. These are the computer sciences, engineering and technology, and mathematics. 


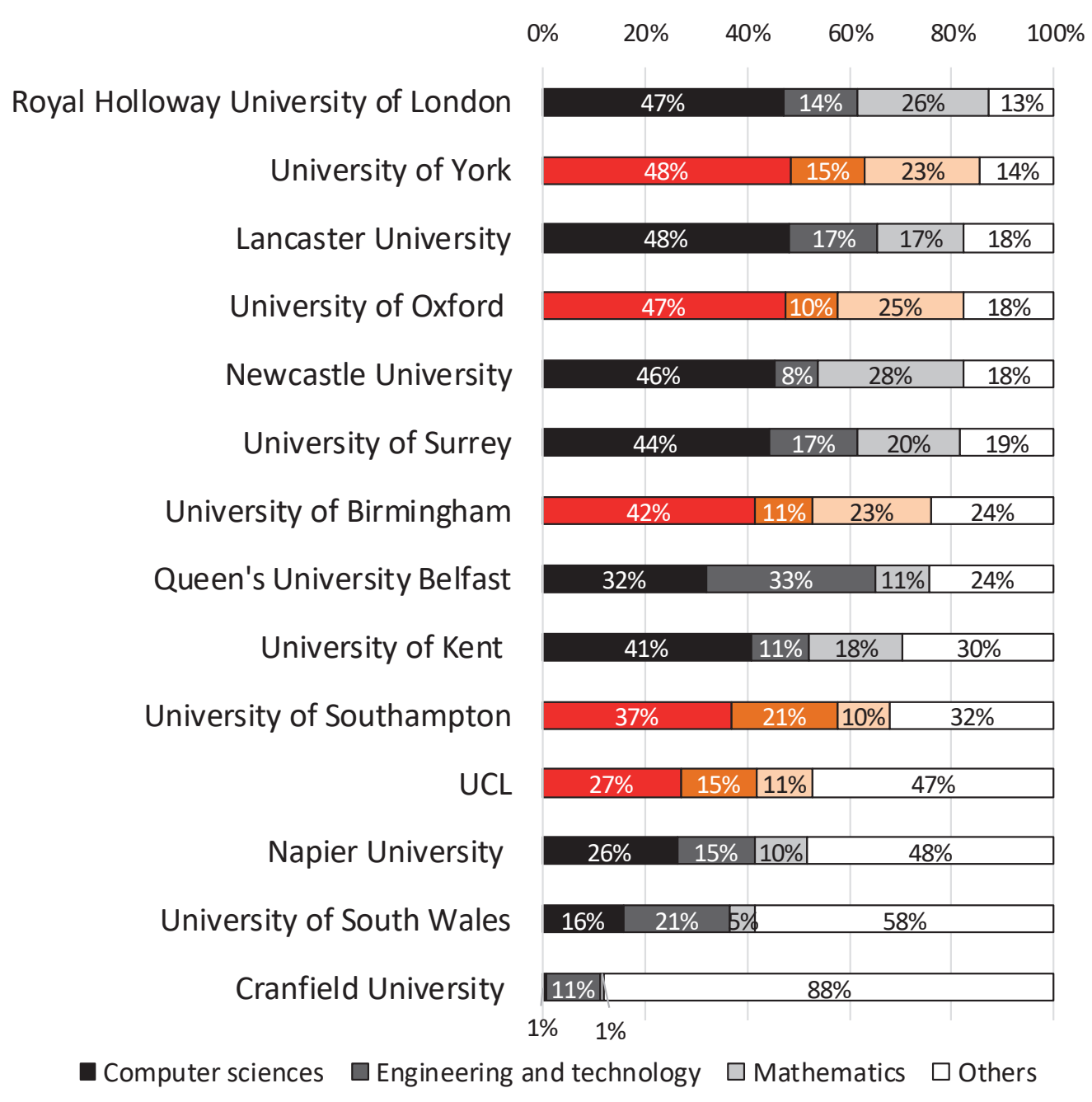

Figure 6: Scientific classification of publications by cyber security researchers and university lecturers

\section{Conclusion}

Recommendations can be made mainly based on the British unified model which can contribute to any cyber security degrees. With respect to the courses, we can say that there are disciplines that are fundamental elements in the British model. Topics of the cryptography and data analysis, computer forensics, and, the introduction of basic mathematical models. These courses would help experts to become familiar with information systems and information security which is essential to managing these systems well. Limitations of the study is that it emphasizes on scientometric data, but this trend can be observed among international university rankings placing a great accent on research focused approach and on ranking methodology using bibliometric data. The aim of the analysis is to compare the highly recognized British cybersecurity master's degrees, which obtained the national certificate. Although the certificate declares the curriculum, significant differences can be seen between the examined universities related to their research performance. The national certificate also places a great accent on the research capacities of these institutions so the study has its aim in identifying common publication patterns and collaboration networks among these academics.

Concerning the academic activities of the lecturers, we can observe that they tend to follow the international trends in their publications as they publish their findings in conference proceedings. The presence at international conferences either as a lecturer or as audience is important from the aspect 
of creating international cooperation as well. Finally, the research findings should be published in conference papers to achieve more readers and gain a higher impact.

\section{References}

[1] BISHOP, M., What Do We Mean By „Computer Security Education?; Proceedings of the 22nd National Information Systems Security Conference, 1999.

[2] Her Majesty's Government, National Cyber Security Strategy 2016-2021, 2016. https:/www.gov.uk/government/uploads/system/uploads/attachment_data/file/567242/nationa 1_cyber_security_strategy_2016.pdf 2016.

[3] LILIENTHAL, G. and NEHALUDDIN, A., Cyber-attack as inevitable kinetic war, Computer Law \& Security Review, Volume 31. Issue 3, pp. 390-400. 2015.

[4] OLIJNYK, N. V., A quantitative examination of the intellectual profile and evolution of information security from 1965 to 2015, Scientometrics, Volume 105. Issue 105, pp. 883-904. 2015.

[5] POLANSKI, P. P., Cyberspace: A new branch of international customary law?, Computer Law \& Security Review, Volume 33. Issue 3, pp. 371-381. 2017.

[6] SAMPSON, F., Chapter 1 - Cyberspace: The new frontier for policing?, in Akhgar, Babak, Staniforth, Andrew, Bosco, Francesca M. (eds.), Cyber Crime and Cyber Terrorism Investigator's Handbook, pp.1-10. 2014.

[7] SPAFFORD, E. F., Teaching the BigPicture of InfoSec; 2nd National Colloquium for Information System Security Education, James Madison University, Harrisonburg, USA 1998.

[8] YURCIK, W. and DOSS, D., Different Approaches in the Teaching of Information Systems Security; Proceedings of the Information Systems Education Conference (ISECON), Cincinatti OH. USA, 2001 